\title{
EL TEATRO LÍRICO COMO GÉNERO DIFUSOR DE LAS IDEOLOGÍAS DOMINANTES EN TORNO A LA GUERRA DE ÁFRICA $(1859-1860)^{1}$
}

\author{
LYRIC THEATRE AS A DIFFUSER GENRE OF THE DOMINANT \\ IDEOLOGIES AROUND THE WAR OF AFRICA (1859-1860)
}

\author{
Andrea García Torres \\ Universidad de Oviedo \\ andreagarto@gmail.com \\ ORCID iD: https://orcid.org/0000-0003-0941-6283
}

\begin{abstract}
Resumen
La mayor victoria propagandística e ideológica de la España isabelina fue la Guerra de Âfrica. La zarzuela juega aquí un papel importante para construir la imagen que se quiso dar entonces del país, y ello a pesar de que la mayoría de estas obras han tenido un éxito reducido. Aunque este trabajo no se plantea como un exhaustivo catálogo de obras, sí incorpora numerosos ejemplos en los que puede verse cómo los títulos de teatro lírico llevan implícito el mismo discurso oficial que difundía entonces el gobierno de O'Donnell. Contribuyen por ello en la construcción y difusión del imaginario colectivo que se implantó en España sobre los marroquíes y el avance colonial, e incluso del propio país dentro del contexto internacional. La supremacía moral, intelectual, religiosa y cultural de los españoles respecto a los musulmanes, junto al descrédito de éstos, articulan el discurso ideológico que se desprende también en este teatro.
\end{abstract}

\section{Palabras clave}

Guerra de África, Batalla de Tetuán, Zarzuela, Teatro lírico, colonialismo, Marruecos, teatro siglo XIX.

El Desastre del 98 y los sucesos anteriores en Cuba han centrado la atención de los estudios sobre música y guerra en el siglo XIX, especialmente porque constituyeron un punto de inflexión en la cultura española. También la pro-

\begin{abstract}
The biggest victory of the Isabelline Spain, from a propaganda and ideological point of view, was the African War. In this regard, the zarzuela plays an important role in the building of the impression that was intended to be given about the country, although most of these plays had a limited success. Even if this paper is set out as an index of works, it includes several examples of how the titles of the lyric theatre present the same official speech presented at the time of the O'Donnell government. Therefore, they help in the building and spread of the collective worldview instituted in Spain about the Moroccan and the colonial advance, and even about Spain itself in the international context. The Spanish moral, intellectual, religious and cultural supremacy about Muslims, along with their disrepute, put together the ideological speech also implied in this theatre.
\end{abstract}

\section{Keywords}

War of África, Battle of Tetuán, Zarzuela, lyric theatre, colonialism, Morocco, $19^{\text {th }}$ theatre.

ducción teatral vinculada con la Guerra de la Independencia (1808-1814) ha despertado interés en el entorno académico por el elevado número de obras conmemorativas que se estrenaron con esta temática. Algunos conceptos como los

1 Este trabajo se incluye dentro del proyecto de I+D Microhistoria de la Música española contemporánea: ciudades, teatros, repertorios, instituciones y músicos (HAR2015-69931-C3-3-P) que se desarrolla en la Universidad de Oviedo, y está financiado por el Ministerio de Economía y Competitividad. 
de patriotismo, heroicidad o gesta, que fueron propugnados en las zarzuelas de los años de la Independencia siguieron estando vigentes también en el teatro lírico coetáneo a la Primera Guerra de Marruecos. La misma que la historiografía del siglo XIX relegó a un segundo plano por considerarla un capítulo exiguo de la historia española, "un proyecto absurdo concebido para distraer a un pueblo crédulo de los problemas creados por sus ineptos políticos liberales"2.

Este primer conflicto en África, iniciado en octubre de 1859 que, tras las batallas de Castillejos y Cabo Negro, culminó con la toma de la ciudad de Tetuán en 1860, produjo en la cultura española una tremenda efervescencia, reflejada en la cancionística popular, en la celebración de corridas de toros de carácter extraordinario y en los estrenos de obras dramáticas de diversa índole, entre las que se encuentra el corpus zarzuelístico que se tratará en este estudio. Marie Salgues estima que, aglutinando todos los géneros, sobre la Guerra de África se escribieron más de ochenta obras dramáticas ${ }^{3}$.

Aunque existe gran interés y un elevado número de publicaciones sobre este conflicto hispano-marroquí desde distintas disciplinas académicas como la historia, la filología, la política e incluso la musicología, apenas se han realizado trabajos científicos que focalicen su atención en el extenso número de zarzuelas y otras obras análogas pertenecientes al teatro lírico que se escribieron a raíz del enfrentamiento y su alto valor ideológico. Cuando éstas han sido objeto de estudio, sólo se han abordado desde un acercamiento filológico, sin ahondar en cuestiones musicales. Tampoco se ha investigado, en relación a estas obras líricas, la coexistencia entre nacionalismo y regionalismo que dominaba la escena política y social ya a mediados del XIX, tal como defienden varios historiadores, y cuyas tensiones aparecen en este teatro musical.

El trabajo realizado por Juan José Pastor Comín ${ }^{4}$ hace un pionero y esclarecedor acopio de himnos, músicas de carácter militar y algunas obras líricas. Señala, basándose en el texto Un testigo de la Guerra de África ${ }^{5}$, la importancia de las manifestaciones musicales en los actos de la vida castrense y en el mismo campo de batalla. No obstante, el suyo es un estudio general que no se limita a los acontecimientos de los años 59 y 60, y hace alusión también a las demás campañas en África en las que España participó posteriormente.

También en la monografía El reino olvidado: Cinco siglos de historia de España en África ${ }^{6}$ se hace una enumeración de obras líricas sobre esta temática que Antonio Ma-

2 SÁNCHEZ-MEJÍA RODRIGUEZ nº 162 (Madrid, 2013): 41. 3 SALGUES (2010): 23.

4 PASTOR COMÍN (2009): 197-222.

5 Véase ALARCÓN, PALORMO (ed.) (2005).

6 CARRASCO GONZÁLEZ (2012). nuel Carrasco lista dentro de lo que él denomina zarzuela africana. Algunos de los títulos musicales que menciona han pasado a formar parte de las investigaciones sobre el tema, y son asimismo objeto de estudio en el presente trabajo.

El texto ya citado de Marie Salgues ${ }^{7}$, escrito desde la perspectiva de la historia cultural, describe el teatro de signo patriótico en la segunda mitad del siglo XIX. Presta especial atención a cuestiones de censura, a los intereses e instituciones que influían en su desarrollo, y a los impedimentos para el estreno de diversos títulos dramáticos. Asimismo, se detiene a analizar los temas que aparecen en estas obras de temática militar, coetáneas al conflicto marroquí, como ocurre con la confrontación de España con Inglaterra por las tensiones existentes entre ambos países por hacerse con el control de la ciudad de Tánger. Sin embargo, a pesar de reconocer el peso que la música tuvo como manifestación nacionalista, el estudio de Salgues sobre el caso de la Guerra de África focaliza la atención en el teatro hablado.

Más reciente es el estudio de Jaime Cárdenas Isasi ${ }^{8}$, en el que enumera diversas zarzuelas de temática africana que se escribieron en las primeras décadas del siglo XX. Su trabajo, planteado nuevamente desde la filología, trabaja exclusivamente con los libretos de las obras, sin mencionar ningún aspecto sobre la música. Según este autor, es especialmente interesante la construcción de género que se puede apreciar en el teatro lírico del momento entre los españoles colonizadores y los árabes colonizados. Influenciados por la tendencia sicalíptica de comienzos de siglo aplicada desde una postura plenamente colonialista, los autores inciden sobre la belleza y sensualidad de la mujer árabe, idealizada habitante del harén, que únicamente se siente atraída por el hombre español y no por los fieros marroquíes, insensibles en temas amatorios.

\section{LA GUERRA DE ÁFRICA EN EL TEATRO LÍRICO: TEMAS E IDEOLOGÍAS}

El principal inconveniente que dificulta el estudio del presente trabajo es la desaparición de una importante cantidad de partituras, lo que provoca que en ocasiones sean el libreto y las referencias hemerográficas las únicas fuentes disponibles en la actualidad. El hecho de que la mayoría de los títulos tuvieran una recepción limitada, en la mayoría de los casos ligada a los acontecimientos puntuales de la gue$\mathrm{rra}^{9}$, y la existencia de un sistema editorial insuficientemente

7 SALGUES (2010): op. cit.

8 CÁRDENAS ISASI (2016): vol. 8, 217-235.

9 PASTOR COMÍN (2009): 200. Menciona en su estudio la función de crónica oficial de los sucesos bélicos que prestaban los sainetes y zarzuelas de los años de la guerra. 
desarrollado, provocó que la difusión de las partes musicales fuese mínima en muchos casos. A esto hay que añadir también que se trata en gran medida de obras de juventud o de autores literarios y musicales muy poco conocidos, y que han tenido un papel más bien secundario en la historia del teatro lírico español. En el caso de los compositores, no se tiene noticia de ninguno de los músicos más destacados de la escena española de mediados de siglo se hayan interesado por esta temática bélica; ni los dedicados a la composición operística, allegados a la reina, ni quienes encauzaron la producción lírica nacional por las vías de la zarzuela, y este hecho condiciona obviamente el alcance de su recepción.

Interesa en este artículo ofrecer un estudio sobre cómo la música y la escena contemporáneas a la Primera Guerra de Marruecos ayudaron a construir el imaginario sobre el proceso bélico, los marroquíes, e incluso sobre la propia imagen de España y de su papel en la carrera colonial. El teatro lírico, de tema más o menos militar, fue cómplice de los argumentos a los que recurre el gobierno de la Unión Liberal y la
Corona durante los meses que dura la ofensiva. Se buscaba convencer a una población de clase media-alta sobre la rentabilidad que supondría el citado enfrentamiento, e influir en la opinión pública. Este trabajo no pretende elaborar un catálogo exhaustivo que recoja cada uno de los títulos escritos alrededor de la Guerra de África, pero sí ofrecer varios ejemplos en los que el teatro lírico actúa como arma propagandística que enarbola argumentos supeditados -voluntaria o involuntariamente- al discurso oficial del gobierno.

Estas obras se centraron principalmente en magnificar las gestas bélicas de las que España salió vencedora, como ocurrió sobre todo en el caso de la ocupación de la ciudad de Tetuán. Algo bastante predecible si se tiene en cuenta que el objetivo político de toda la ofensiva en África era poner la ciudad bajo dominio español. Los autores dramáticos se sumaron al ensalzamiento patriótico que acompañó a todo el conflicto. Basta comprobar las carteleras de los teatros madrileños los días sucesivos a la caída de Tetuán el 6 de febrero de 1860 para percatarse del interés por programar títulos que aludiesen a África.

\begin{tabular}{|c|c|c|c|c|c|}
\hline Teatro Real & $\begin{array}{c}\text { Teatro de la } \\
\text { Zarzuela }\end{array}$ & Teatro Novedades & Teatro del Circo & $\begin{array}{l}\text { Teatro del } \\
\text { Príncipe }\end{array}$ & Teatro Francés \\
\hline - Luisa Miller & $\begin{array}{l}\text { - El juramento } \\
\text { - Tetuán por } \\
\text { España } \\
\text { - El Diablo las } \\
\text { carga }\end{array}$ & $\begin{array}{l}\text { - La toma de } \\
\text { Tetuán } \\
\text { - Baile } \\
\text { - La toma de } \\
\text { Tetuán } \\
\text { - Baile }\end{array}$ & $\begin{array}{l}\text { - Adriana } \\
\text { - Vanidad y } \\
\text { pobreza } \\
\text { - Un recluta de } \\
\text { Tetuán }\end{array}$ & $\begin{array}{l}\text { - Los moros del } \\
\text { Riff } \\
\text { - Baile } \\
\text { - Las tramas de } \\
\text { Garulla } \\
\text { - La luna de hiel } \\
\text { - Baile } \\
\text { - Escenas de } \\
\text { campamento }\end{array}$ & $\begin{array}{l}\text { - Mademoiselle } \\
\text { mon frère } \\
\text { - Le Bougeoir } \\
\text { - La toma de } \\
\text { Tetuán } \\
\text { - Les mels melo de } \\
\text { la rue Meslay } \\
\text { - Deux dames au } \\
\text { violon }\end{array}$ \\
\hline
\end{tabular}

Tabla 1. Programación ofrecida en los teatros de Madrid el día 12 de febrero de $1860^{10}$.

Para los autores el tema de la guerra contra Marruecos se convirtió también en una estrategia comercial que les permitió utilizar las circunstancias del conflicto para estrenar nuevas obras, aunque muchas de ellas tuvieron escaso éxito y contaron con la desaprobación de la crítica. Por otro lado, el corpus dramático que se generó entonces se sumó a las manifestaciones propagandísticas que sobre la ofensiva difundió el gobierno isabelino, por ejemplo, a través de la prensa. La ventaja del teatro respecto a ella, era que tenía acceso a un segmento de la población mucho mayor por la conocida cuestión del elevado índice de analfabetismo, que en el caso de los habitantes de Madrid rondaba el $60 \%$ en $1860^{11}$.

10 ANÓNIMO, 1.708 (Madrid, 1860): 4.

11 GUEREÑA, 288 (Madrid, 1989): 185-236.
Se sabe que José Bonaparte fomentó la apertura de los teatros durante la Guerra de la Independencia a través de subvenciones a las compañías y gratificaciones personales a algunos artistas ${ }^{12}$. Sin embargo, no hay fuentes certeras que muestren si sucedió lo mismo con Isabel II en este primer enfrentamiento hispano marroquí, ya que la prensa, que sí había informado previamente sobre el tema durante los años de lucha contra los franceses, no publica ahora ninguna información al respecto. Por ello, no es posible afirmar si la iniciativa de escribir sobre la Guerra de Marruecos proviene

12 María Mercedes Romero Peña cita en su texto los datos aportados por Emilio Cotarelo en Isidoro Máiquez y el teatro de su tiempo (1902). ROMERO PEÑA (2006). 
de los mismos autores, o es una imposición de la administración. No obstante, es interesante señalar el modo en que el gobierno de O' Donnell supo centrar la atención pública de su política de expansión colonial en este conflicto del que España salió victoriosa, mientras silenciaron los problemas con las revueltas e insubordinaciones independentistas que se produjeron en Cuba durante los años previos a la Guerra de los Diez Años ${ }^{13}$. Otra diferencia importante con la Guerra de la Independencia es que durante los meses que dura el conflicto en África, no hay un teatro satírico que canalice las opiniones escépticas sobre el enfrentamiento.

Aunque no hay evidencias sobre la promoción gubernamental de este teatro lírico, debe entenderse esta Primera Guerra de Marruecos como "una continuación de la política por otros medios" 14 por el modo en que el discurso oficial trasciende a los títulos que aquí se van a tratar. Este enfrentamiento bélico contra el sultanato marroquí fue para España una maniobra para mejorar la imagen del entonces erosionado régimen isabelino. Se ha afirmado que la toma de Tetuán no supuso ninguna mejora económica para el país, pero sí sirvió para autoconvencerse de que era España quien tenía "el derecho y el deber de dominar y civilizar el mundo" ${ }^{15}$. El teatro sirvió en este momento para elevar a la categoría de mito los acontecimientos bélicos, como un campo de batalla alternativo en el que convencer a la población de que cada una de las vidas perdidas en tierras africanas era un sacrificio necesario para que España recuperase su posición entre las potencias mundiales dominantes; de ahí las referencias recogidas en la prensa y en el teatro sobre la vinculación de Isabel II con Isabel la Católica.

A pesar de los intereses del gobierno por magnificar la empresa expansionista africana y la conquista de la ciudad de Tetuán, no existió una operación propagandística dirigida desde el propio Estado como sí ocurriría con los totalitarismos en el siglo XX. No hubo una acción teatral coordinada e impulsada por el propio gobierno, que contase con el favor de la élite artística en los círculos musicales. Con respecto a esta guerra con Marruecos, el conjunto de iniciativas que se llevaron a cabo desde el teatro lírico partieron principalmente de ideas particulares posicionadas del lado del vencedor, o que aprovecharon un tema de actualidad, como lo fue esta guerra, para obtener beneficios económicos. Sin embargo, no es sencillo localizar aquellas opiniones opuestas de las clases populares que pudieran surgir en relación a este conflicto, bien por cuestiones de censura, que se encargó de revisar todas las obras que más tarde se mencionan, o por el

13 Véase DOMINGO ACEBRÓN, 74 (Toulouse, 2000): 105117 y STUCKI (2017).

14 CLAUSEWITZ (2005): 171.

15 ÁLVAREZ JUNCO (2001): 441. entramado propagandístico que la prensa y las manifestaciones culturales construyeron.

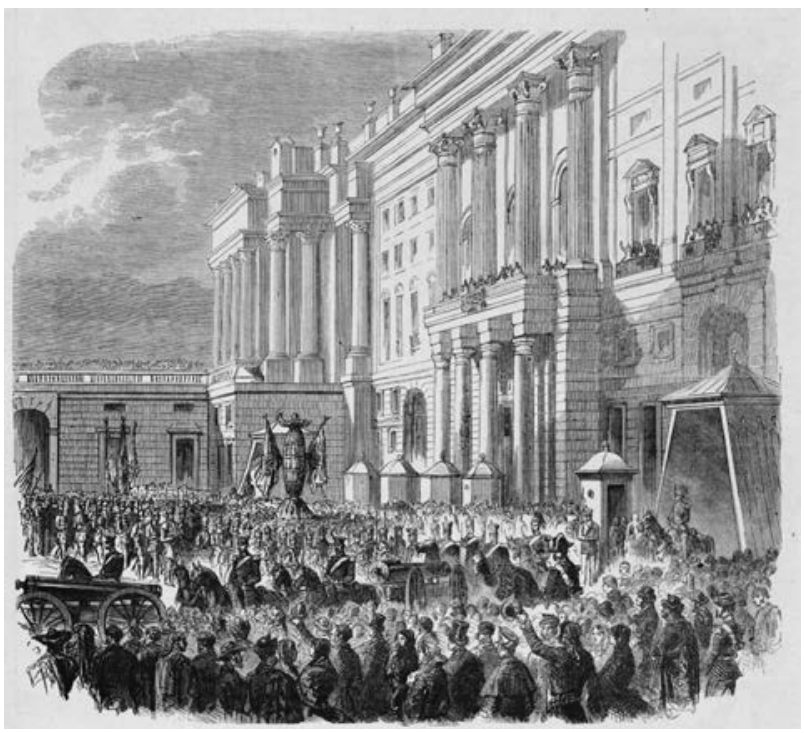

Imagen 1. Presentación a S. M. La reina de España de los trofeos de la Guerra de Marruecos ${ }^{16}$.

Cabría imaginar que la grandiosidad y el elemento espectacular fuesen dos cuestiones importantes para un teatro lírico que se quiere calificar de patriótico, y que quería mostrar en escena la gloria de un país en guerra que más tarde se proclamaría vencedor. Marie Salgues menciona en su trabajo que la espectacularidad es una de las señas de identidad que caracterizan al teatro patriótico ${ }^{17}$, aunque en el caso de las obras líricas inspiradas en la Primera Guerra de Marruecos el tipo de títulos que predominan son de pequeño formato, escritas en su mayor parte en un único acto y con un limitado número de personajes. Sólo se enfatiza el elemento escénico en los títulos de las dos últimas décadas del siglo XIX, que se enfrentan al conflicto de 1859 con cierta retrospectiva, lo que respalda la hipótesis anterior de las iniciativas individuales en el teatro lírico, realizadas en ocasiones sin demasiados medios. El estudio de caso que se realizó sobre el impacto de esta guerra en la ciudad de Sevilla deja constancia del carácter local de las manifestaciones al apuntar que las celebraciones, festejos y otros actos oficiales se organizaron a instancias del Ayuntamiento ${ }^{18} \mathrm{y}$ no por un mandato a nivel nacional.

16 ANÓNIMO, 376 (París, 1860): 181.

17 Véase SALGUES (2009): op. cit.

18 SOMÉ LASERNA (2012): 8. 
La incorporación de salvas a la gloria nacional es otra de las características de este grupo de obras líricas, si bien es cierto que el grado de exaltación disminuye según la composición de éstas se aleja temporalmente de la guerra. Cualquier momento es bueno para apelar al sentimiento popular con vítores sobre las glorias de la nación, especialmente al término, para exaltar aún más los ánimos de los espectadores por las victorias en Marruecos y conducir al éxtasis final de la representación. De hecho, la crítica coetánea no alberga dudas al señalar que la principal razón por la que estas zarzuelas tuvieron un éxito relativo fue por la situación inusual en la que se encontraba España entonces. La crítica las catalogó en su mayoría como obras circunstanciales, incluso como disparates, añadiendo que su calurosa pero fugaz acogida se debió a la predisposición que sentía el público por todo lo relacionado con la victoria española, y los comentarios peyorativos no tardaron en aparecer en la prensa.

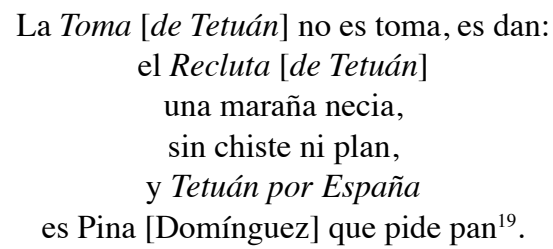

La temática de las obras líricas escritas en torno a la guerra apenas ofrece novedad en comparación con otros conflictos en el siglo XIX; el reconocimiento social de servir en el ejército, la amenaza de la religión musulmana, la recuperación de las glorias nacionales pasadas son sólo algunos de los temas que se abordan. Como se verá más adelante, también existen varios casos en los que únicamente el título de estas obras teatrales hace referencia a la Guerra de África, mientras el desarrollo argumental apenas mantiene relación, y su temática se acerca más a la de un sainete tradicional que a la proclama nacionalista exaltada que cabría esperar del teatro patriótico, en el que abundan las escenas de asalto y una dramaturgia orientada a la recreación de las hazañas bélicas ${ }^{20}$.

Se ha dicho también que la guerra con Marruecos fue una cuestión religiosa además de una lucha política, una especie de nueva Reconquista o "misión santa" ${ }^{21}$ que hiciera a los musulmanes abandonar su conducta infiel y amoral para

19 ANÓNIMO, 11 (Madrid, 1860): 84.

20 SALGUES (2009): op. cit. es quien menciona en su trabajo sobre la relación que el teatro bélico mantenía con la espectacularidad en la escena teatral.

21 R. R. De M. (1860): 2. alienarse en los valores cristianos. La importancia de este tema es manifiesta en todas las zarzuelas coetáneas. Es por culpa de la cuestión religiosa, y la otredad cultural, por la que los musulmanes aparecen en estas obras caracterizados como seres feroces y primitivos. Asimismo, los libretos dejan constancia de que las batallas se ganan gracias a la ayuda que Dios proporciona a sus fieles. La cuestión religiosa $-\mathrm{y}$ social- en los títulos aquí abordados también se deja sentir en temas como la poligamia y la cuestión de los harenes en los que vivían las mujeres, que ya llamaban sobremanera la atención de los autores en los meses de la guerra mucho antes de que en la escena española irrumpiera la sicalipsis, que llevaría el exotismo y la sensualidad a su máxima representación.

Aunque en menor medida, las colonias americanas también han aportado títulos cuya temática se inspira en esta Guerra de África. Es el caso de Los heridos del Serrallo, apropósito lírico-dramático en 1 acto $^{22}$, escrito y publicado en 1860 en La Habana por autores cubanos como fueron Ramón Barrera y Narciso Téllez ${ }^{23}$. La temática no difiere apenas de las obras estrenadas en España, ya que muestra las mismas situaciones que los títulos representados aquí -honor de los combatientes, sacrificio de sus seres queridos en favor de la defensa de la patria-, con la particularidad de que reduce la agresividad a la hora de hablar de los marroquíes.

Las obras líricas que se abordan en este estudio son tratadas desde la perspectiva de la historia cultural, poniendo en relación las partituras -en caso de conservarse- y los libretos, con los acontecimientos políticos y la ideología dominante impuesta desde el Estado. Sólo se han tenido en cuenta los títulos dramático-musicales que aluden a la guerra de 1859-60, excluyendo otros enfrentamientos posteriores, y aquellas obras teatrales que cuentan con música incidental. Asimismo, se ha acotado el periodo de estudio a la segunda mitad del siglo XIX, y hasta 1913 cuando Tetuán vuelve a ser ocupada por los españoles. Las fuentes aquí estudiadas proceden de la Biblioteca Nacional de España y del Archivo de la Sociedad de Autores.

22 Los heridos del Serrallo. Apropósito lírico dramático en 1 acto. Barrera, Ramón, La Habana, Viuda de Barcina, 1860.

$<$ https://books.google.es/books?id=vGMOAAAAYAAJ\&prints ec $=$ frontcover $\& d q=l o s+h e r i d o s+d e l+$ serrallo $\& h l=e s \& s a=X \& v e d=0 a h$ UKEwic08qmvpbXAhXHtBQKHXEuCPIQ6AEIJzAA\#v=onepage\&q $\& \mathrm{f}=$ false $>$ [consultado: 29-10-2017].

23 Del libretista Ramón Barrera no se ha localizado información alguna. Por su parte, Narciso Téllez fue un músico reconocido en Cuba a mediados de siglo, autor de Tratado teórico de música (1868). CARPENTIER (1987): 294. 


\section{LAS OBRAS LÍRICAS ESCRITAS EN TORNO A LA PRIMERA GUERRA DE ÁFRICA}

\subsection{Los cazadores de África. La zarzuela en los comienzos del conflicto}

A las pocas semanas de que España declarara la guerra a Marruecos se estrena esta obra en el Teatro de la Zarzuela de Madrid, concretamente el 15 de noviembre de $1859^{24}$. Se trata de una obra alentadora y de clara exaltación nacionalista, cuyos números de música recurren siempre a un tono hímnico, con reiteradas salvas a España. Es una obra estructurada en un único acto, que apenas tuvo repercusión en la prensa.

El argumento se contextualiza en Ceuta, en la Sierra de Bullones. La batalla de la que se hace eco este título fue la que tuvo lugar en dicho emplazamiento en diciembre de 1859 , fue el primer enfrentamiento entre el ejército marroquí y el español, quien finalmente se alzó con la victoria. Este acontecimiento es lo que le da a esta zarzuela ese sentido festivo que se puede extrapolar a la casi totalidad del teatro lírico escrito en torno a esta Guerra. Los cazadores de África, deja constancia en escena de la trifulca en el campo de batalla y la fiereza de los militares españoles, ya que es una de las pocas obras que va a incorporar escenas de lucha explícita durante la representación.

El título de esta zarzuela está tomado por el batallón de Cazadore $^{25}$ de Madrid, que fue especialmente beligerante, y por ello todo un ejemplo a seguir para los demás soldados, porque incluso antes de declararse formalmente la guerra ya habían llevado a cabo enfrentamientos con las cabilas mo$\mathrm{ras}^{26}$. Al comienzo del libreto se menciona que la guerra en Marruecos es contra los moros, las mujeres musulmanas quedan al margen, y ya se hace alusión al atractivo físico de las nativas. De todas formas, el papel de éstas en Los cazadores de África, queda reducido a ser un mero señuelo que atrae al capitán español hasta la trampa enemiga. En el extremo totalmente opuesto está la mujer española, simbolizada en el personaje de Elisa, que destaca por su valentía para adentrarse incluso en el campo de batalla, vestida como un soldado más, con refuerzos para salvar a su amado y a su patria.

La partitura, desaparecida, cuenta con un total de 3 números de música, y hay en ella una cita a las seguidillas

24 ANÓNIMO, 80, (Madrid, 1859): 4.

25 La denominación hacía referencia a uno de los cuerpos de artillería ligera que participaron en esta guerra. No obstante, es cierto que el término cazadores estaba ya denostado por sus connotaciones un tanto salvajes. ALMIRANTE (1869): 248-249.

26 ALARCÓN, PALORMO (ed.) (2005): op. cit. manchegas pertenecientes al folclore tradicional de Castilla La Mancha. Las mismas que en 1864 utilizaría Francisco Barbieri en su zarzuela Pan y toros, y que desde entonces se han convertido en un recurso muy habitual para representar a La Mancha en el teatro lírico, sin que en ningún momento en Los cazadores de África se tome esta región como representativa del total de España.

\subsection{Tetuán por España y la demonización mora}

En el caso de Tetuán por España, zarzuela nuevamente en 1 acto, con letra de Mariano Pina y música de Cristóbal Oudrid, Javier Gaztambide y Luis Martín, la crítica la describió como una improvisación sin pretensiones ${ }^{27}$. Estrenada en el Teatro de la Zarzuela probablemente el 8 de febrero de $1860^{28}$, se mantuvo en la programación al menos hasta el día 19 de febrero ${ }^{29}$. El estreno de este título tiene un carácter extraordinario que irrumpe en la programación con motivo de la celebración de la victoria, desplazando los demás títulos. El grito ¡Tetuán por España! se había convertido en toda una proclama de marcado signo nacionalista que la prensa coetánea se encargó de difundir masivamente. Con seguridad un joven Pina Domínguez, colaborador entre otros medios de $L a$ Correspondencia de España, uno de los diarios que, durante el enfrentamiento con Marruecos iniciado en octubre de 1859, se puso al servicio de la Unión Liberal del general Leopoldo $\mathrm{O}^{\prime}$ Donnell ${ }^{30}$, y donde sin lugar a duda lo habría visto Pina.

Desde el punto de vista argumental, el libreto expone de forma maniquea las relaciones entre españoles y marroquíes durante la guerra. Durante la conquista de Tetuán un capitán del ejército español es capturado por el enemigo que, en un fingido arrebato de compasión le libera, no sin antes tenderle una trampa para acabar con su vida, aunque sin éxito. Describe Pina en este argumento el tipo de enemigo despiadado, vengativo y traicionero al que se enfrentaba el ejército español. Un estereotipo muy extendido durante los meses de conflicto en la literatura coetánea ${ }^{31}$, que arraigó en

27 ANÓNIMO, 4.143 (Madrid, 1860): 4.

$28 \mathrm{El}$ dato ha sido tomado de una inscripción que figura en una de las particellas de este título que se custodia en el archivo de la SGAE en Madrid (caja 998), y coincide con los datos aportados por la prensa, que sólo recoge información a partir de esta fecha. No obstante, también en la parte del personaje de Carlos manuscrita aparece como fecha de estreno el día 18 de enero de ese mismo año.

29 Esta es la última fecha de la que se tienen noticias en la cartelera, según la prensa. Gamayo, F., "Espectáculos", La regeneración, 1.467 (Madrid: 1860): 4.

30 Sobre la inclinación política de La Correspondencia puede consultarse la herramienta descriptiva que propone la Hemeroteca de la BNE.

31 LÓPEZ BARRANCO (2003). 
el imaginario colectivo del momento, y permaneció vigente en las obras líricas de los sucesivos enfrentamientos ${ }^{32}$. Desde el comienzo de la obra se aprecia una historia fabulada, con escaso interés por ofrecer un testimonio veraz de los hechos y de los participantes de ambos bandos; no hay un proceso de documentación sobre los marroquíes y abusa de los tópicos arbitrarios establecidos en el imaginario español, adoptando una postura colonialista que sitúa en este caso al enemigo musulmán en una posición de inferioridad moral.

Con esta visión distorsionada del mundo árabe, su cultura y su religión, se justifica aquí ante la nación española la legitimidad de irrumpir en el escenario marroquí, ejercer dominación en el plano hegemónico sobre el territorio y ostentar el control político. Una postura imperialista muy extendida en torno a la primera Guerra de África y que acerca a España a las posiciones que, sobre Asia, adoptaron las potencias occidentales en el siglo XIX ${ }^{33}$.

Los personajes son prototipos de la literatura del momento inspirada en este conflicto. Hay dos de ellos completamente opuestos en torno a los que gira toda la trama, el primero es Mahomad, un líder y señor del ejército marroquí, al que acompañan sus sicarios. Su carácter es despreciable, tanto con sus esclavos como con Carlos, el capitán español que mantiene prisionero. Uno de los aspectos que no pasan desapercibidos en el libreto es el modo en que Mahomad trata a Zaida, como un objeto que se vende o compra. Con ello se quiere marcar una distancia entre las culturas cristiana y musulmana en lo que a la consideración de la mujer se refiere, degradando su posición social, y en última instancia, dando a los musulmanes un aspecto de bárbaros por consentirlo. Paradójicamente, entonces en España las libertades para la mujer no eran especialmente amplias ${ }^{34}$. El capitán español, Carlos, y el soldado Francisco son tratados como héroes nacionales: tienen sentido del deber y compañerismo, luchan contra el opresor por imponer justicia, y lo hacen en nombre de España. Finalmente, Zaida es un personaje secundario, paradigma de la mujer árabe que se proyectó para la sociedad española del momento; esclava de Mahomad, fascinada por Carlos y su promesa de libertad, recae sobre ella el componente exótico de la trama. Un perfil que coincide exactamente con el propuesto en el teatro lírico de las primeras décadas del siglo XX, en el que Cárdenas advierte

32 CÁRDENAS ISASI (2016): op. cit.

33 QUINTERO CALVACHE, 22 (Santiago de Cali, Colombia, 2015): 119-137.

34 A pesar de que el estudio comienza en la etapa posterior de la Restauración Alfonsina, en la que la sociedad española era algo distinta a la contemporánea a Isabel II. NASH (1983). sobre "la variable de género" 35 a la hora de representar al "Otro" según sea mujer u hombre.

Desde el punto de vista musical, cuenta con un total de 4 números cantables. A la hora de clasificar formalmente esta zarzuela, puede verse que recurre al formato en un acto, más característico de los años 30 del siglo XIX denominado zarzuela romántica ${ }^{36}$, que aún seguía vigente en los teatros durante la década de los 50 , a pesar de la aparición de los nuevos modelos de inspiración francesa que comenzaron a imponerse a partir del estreno de Jugar con fuego en 1851 .

En la partitura no hay una utilización profusa de danzas populares, que sí van a estar presentes en títulos posteriores en los que se aborda el tema de la Guerra de África, especialmente durante las décadas en las que predomina en los teatros el género chico. Tampoco se trata de una escritura operística propiamente dicha, por la sencillez de los acompañamientos y de la propia línea melódica, cercana a la escritura popular. La excepción en este caso son la polka del $\mathrm{n}^{\circ} 2$ y la utilización de la habanera-denominada tango por los propios autores, como era habitual- que aparece en dos de los números de esta zarzuela. En el $n^{\circ} 3$, un tango descontextualizado ${ }^{37}$ que incorpora el característico ritmo apuntillado, cuyas secciones se van intercalando con otras escritas en compás de 3/8. El coro que interviene en el $n^{\circ} 3$ de Tetuán por España es enteramente masculino, con dos voces de tenores y una de bajos, representa a los moros defensores de la ciudad. Todo lo contrario que en los títulos finiseculares, cuando las coristas sean quienes caractericen al ejército.

El asunto militar tiene una presencia continua en este título, hasta el punto de que incluye una banda militar externa a la partitura con los números de música de esta zarzuela, y que interpreta un pasodoble instrumental de marcado carácter marcial ${ }^{38}$, pero cuyo momento de aparición en la obra no está aún claro.

35 CÁRDENAS ISASI (2016): op. cit.

36 Así la denomina $\mathrm{M}^{\mathrm{a}}$ Encina Cortizo, que la ubica entre los años de 1832 y 1849, aunque a juzgar por la asiduidad con la que aparecen estas obras en las programaciones que anunciaba la prensa, cabría considerar la perdurabilidad del género y la composición de nuevos títulos también durante toda la década de los años 50 del siglo pasado. CORTIZO RODRÍGUEZ (1995): 161-193.

37 Véase la clasificación temática que se establece en SÁNCHEZ, vol. 3, 1 (Bogotá, 2007): 4-26.

$38 \mathrm{La}$ instrumentación incluye cornetines $1^{\circ}$ y $2^{\circ}$, clarinetes $1^{\circ}$ y $2^{\circ}$, requinto, flautín, bajo $1^{\circ}$ y $2^{\circ}$, bombardino, trombones, $1^{\circ}, 2^{\circ}$ y $3^{\circ}$, trombas $1^{\circ}, 2^{\circ}$ y $3^{\circ}$, bombo, cornetín $1^{\circ} 2^{\circ}$ y $3^{\circ}$, trompas $1^{\mathrm{a}}$ y $2^{\mathrm{a}}$. Véase las particellas de Tetuán por España, Archivo de la Sociedad General de Autores y Editores, Madrid (SGAE), Materiales de orquesta, Caja 998. 


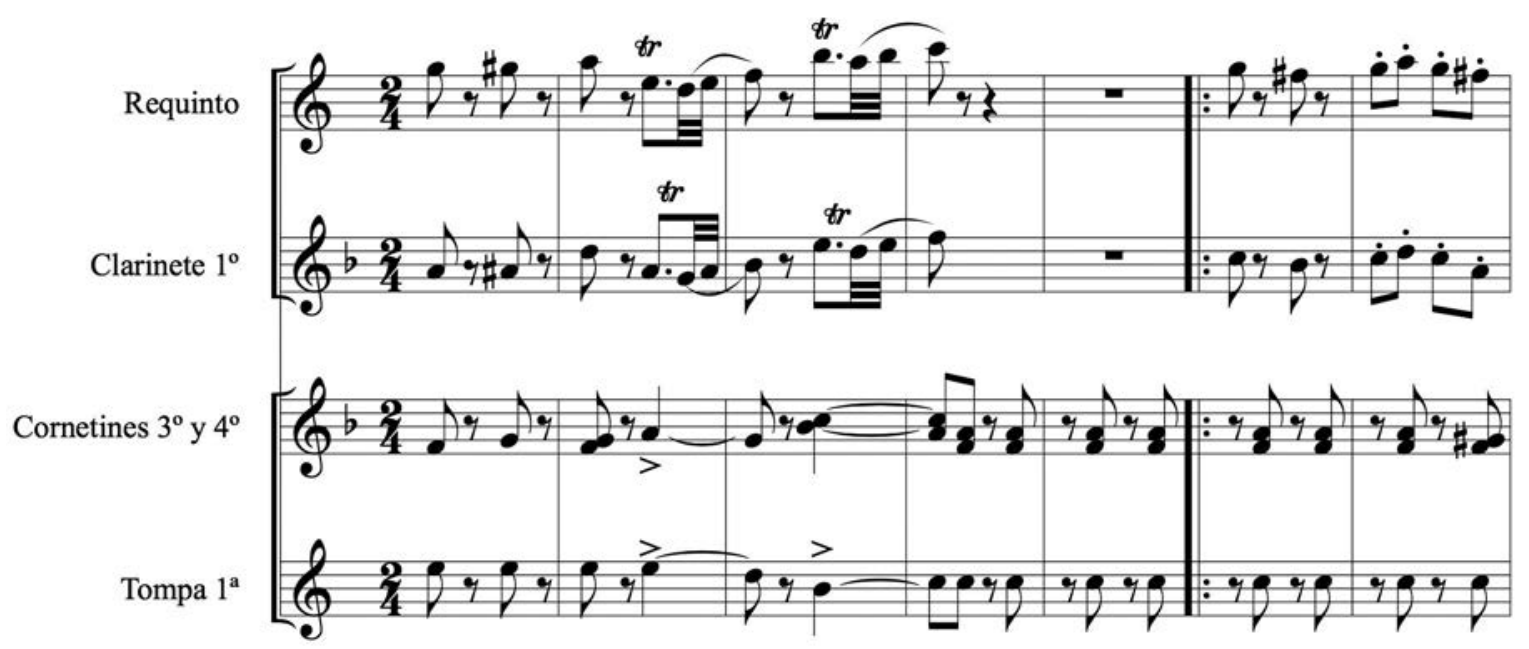

Ejemplo 1. Primeros compases de una selección de instrumentos que constituyen la banda militar que se incluye en Tetuán por España. (cc. 1-7).

Dice Barbieri en sus Apuntes biográficos respecto a Tetuán por España ${ }^{39}$ que, Francisco Salas, entonces empresario del Teatro de la Zarzuela, había previsto la celebración de la toma de Tetuán con la representación de esta obra. El mismo Barbieri señala además el modo en que los tres autores participantes en esta partitura se repartieron la composición de los números de música que la conforman:

\begin{tabular}{|l|}
\hline $\mathrm{N}^{\circ}$ 1. Preludio y canción de Zaida, de Luis Martín \\
\hline $\begin{array}{l}\text { No } 2 \text {. Polka de autor francés, que había traído Gaztambide } \\
\text { de París }\end{array}$ \\
\hline $\mathrm{N}^{\circ}$ 3. Duo de Carlos y Zaida, de Javier Gaztambide \\
\hline $\mathrm{N}^{\circ}$ 4. Coro y coplas, de Mariano Vázquez \\
\hline $\mathrm{N}^{\circ}$ 5. Duo de Francisco y Jalijalaija, de Oudrid \\
\hline $\begin{array}{l}\mathrm{N}^{\circ} \text { 6. Pasodoble que interpretó la banda del Regimiento } \\
\text { de Almería }\end{array}$ \\
\hline
\end{tabular}

Tabla 2. Organización formal de Tetuán por España. Zarzuela en 1 acto (1860).

Continúa el músico haciéndose eco del escaso interés que despertó este apropósito -que el propio Barbieri califica como despropósito-. "Su estreno, a pesar de las favora-

39 CASARES (1994): vol. 2, 93-94. bles circunstancias, fue poco satisfactorio, pero lo que en la misma noche gustó mucho más fueron las poesías que se leyeron" ${ }^{40}$.

\subsection{La toma de Tetuán. La mayor empresa de la Guerra de África y su persistencia en el teatro lírico coetáneo}

Si hay un título predominante en el teatro estrenado durante e inmediatamente después de la Guerra de África es La toma de Tetuán. La prensa, en la que aparecieron numerosos artículos bajo este titular narrando la conquista de la ciudad, actuaba entonces como un aparato ideológico ${ }^{41}$ controlado por el estado ${ }^{42}$ para aleccionar a la burguesía dominante. Los periódicos sirvieron una vez más como inspiración a los autores teatrales, tanto líricos como dramáticos, y entre estos últimos se encuentra El prisionero cristiano o la toma de Tetuán, publicado en Soria en $1860^{43}$. El argumento, bastante análogo con el libro de Pina anterior, también deja

$40 \mathrm{Ibid}$.

41 En el sentido que propone Althusser como el suministrador diario de nacionalismo, en este caso. ALTHUSSER (1988).

42 SOME SALERNA (2012) describe el modo en el que la prensa se pliega a las exigencias de la campaña mediática de gobierno de O’Donnell.

<https://www.academia.edu/9665656/La_Guerra_de_África_en_Sevilla_fervor_patrio_y_opinión_pública> [consultado 03-042017].

43 PÉREZ RIOJA (1906): 2. 
patente el patriotismo y valentía españolas frente a la vileza de los marroquíes.

La función que desempeñaba este teatro alrededor de la Guerra de África, y más aún aquellos títulos que se ponían en escena modestamente como éste, era la de llegar a las clases sociales más populares. Fue el propio autor, Bonifacio Pérez-Rioja quien dejó constancia en sus Memorias teatrales $^{44}$ del modo, más diletante que profesional, en que se llevaban a cabo las representaciones de estas obras, asegurando que "en el espacio de 3 días realicé la hazaña; ocho después lo representábamos varios chicos aficionados, en un teatro casero, con sus correspondientes decoraciones de papel" ${ }^{45}$.

\subsubsection{Diálogos entre nación y región}

La toma de Tetuán, improvisación lírico-bilingüe en un acto y en verso está escrita en valenciano casi en su totalidad, con texto de Rafael María de Liern y música de Joaquín Miró $^{46}$, un compositor totalmente desconocido del que apenas existen datos. La principal diferencia de este título con los demás es que no se centra en aclamar tanto la gloria nacional como la regional. No renuncian nunca a su condición de españoles y se declaran a favor de la intervención bélica gubernamental, pero ello no les impide exaltar en escena las raíces valencianas de los protagonistas de la obra. Esta postura coincide con la propuesta que Borja Riquier ${ }^{47}$ expone en sus estudios sobre la problemática nacionalista en el siglo XIX y la posibilidad de la existencia de otros nacionalismos alternativos al español ${ }^{48}$.

En el caso de la Guerra de Marruecos se suceden las iniciativas locales y regionales de apoyo a la causa nacional, por ello es frecuente encontrar zarzuelas, como ésta, estrenadas en provincias y cuya difusión no trasciende los límites de la región. Convive así con el sistema teatral centralizado en Madrid y Barcelona que es más frecuente encontrar en España durante el siglo XIX ${ }^{49}$, en el que las obras sólo llegaban a las provincias tras haberse presentado en ambas ciudades. Títulos como éste, se escribieron y estrenaron con fines únicamente locales, por lo que no hay indicios de que el gobierno central tuviera ningún tipo de estrategia unitaria

44 Ibid.

45 Ibid. 13.

46 Liern debió escribir La toma de Tetuán antes de trasladarse a Madrid en 1868, cuando aún residía en Valencia. Del compositor Joaquín Miró, con el que colaboró puntualmente en este título, no hay referencias.

47 RIQUIER, 20 (Valencia, 1994): 97-114.

48 ÁLVAREZ JUNCO, 40 (Valencia, 2001): 29-51.

49 MOISAND (2013). para este tipo de manifestaciones culturales durante la campaña marroquí ${ }^{50}$.

Cuando Liern escribe La toma de Tetuán aún no se había trasladado a Madrid. Publicaba artículos en el periódico satírico El Saltamartí en Valencia, que comenzó a publicarse el mismo año de $1860^{51}$. Probablemente la obra se estrenó entonces, tras haber traspasado el ejército español los muros de la ciudad de Tetuán, pero no hay datos que lo confirmen salvo por la fecha de la edición en $1861^{52}$. Por otro lado, la partitura de Joaquín Miró no se ha localizado y no se han encontrado noticias en los diarios coetáneos, quedando como única fuente de estudio este libreto.

La noticia de la toma de Tetuán se difundió velozmente a través de la prensa, auténtico órgano propagandístico de la campaña militar africana, y el título se hizo extensible a un considerable número de obras estrenadas en toda la geografía española. Hay noticia de otra zarzuela titulada igualmente La toma de Tetuán, una obra de gran espectáculo -por esta descripción precisamente es por lo que no se corresponde con la de Liern-, programada en el Gran Café del Universo de Mallorca el 2 de marzo de $1860^{53}$.

La acción propuesta por Liern, se desarrolla en San Esteban de la Venta (Valencia), en el mismo mes de febrero en que se da por concluida la Guerra de África. Narra los momentos previos antes de la Toma de Tetuán, y el júbilo con el que se recibe la noticia en este pueblo de la huerta valenciana. Desde el coro inicial, hay una intención de desacreditar culturalmente a los marroquíes, y hacen especial hincapié en su lengua y sus costumbres. A diferencia de la zarzuela Tetuán por España de Pina Domínguez antes comentada, aquí no hay personificación del enemigo, sino que se generaliza sobre la bravura con la que los musulmanes atacan y la rapidez con la que retroceden ante el avance español. Se caracteriza por la crudeza con la que los personajes, como el Tio Verderol, hablan de "matar moros" con el propósito de legitimar con ello la nacionalidad española, pero en la obra también se pueden ver las notas cómicas propias de los sainetes de costumbres en los que abundan los personajes humildes. No obstante, en este título no hay una profundización psicológica de los protagonistas, y la trama se centra en el mero diálogo sobre asuntos de actualidad.

50 RIQUIER, 20 (Valencia, 1994): op. cit. 51 GUILLAMET I LLOVERAS (2003).

52 La Toma de Tetuán. Improvisación en un acto y en verso. Liern, Rafael María, Valencia, Imprenta de José Ruiz, 1861, BNE, $\mathrm{T} / 19675$.

53 ANÓNIMO, 913, (Palma de Mallorca,1860): 4. 


\subsubsection{La Toma de Tetuán. La recuperación del honor a través de la guerra}

Con el mismo fin laudatorio que las anteriores en lo que a la irrupción española en Tetuán se refiere, escribieron el libretista Juan de Alba y el músico Carlos Llorens su episodio lírico-dramático en 2 actos estrenado en el Teatro Novedades de Madrid, dedicándoselo incluso al propio O’Donnell. Con esta nueva obra en dos actos, ajustada al modelo de zarzuela restaurada propuesto en la obra de Hernando ${ }^{54}$, queda reflejada la diversidad formal que admitía en general el teatro lírico español hacia mediados de siglo, y este tema de la Guerra de Marruecos en particular.

Cuando Carlos Llorens y Robles comenzó a trabajar en este título al final de su vida, había sido ya un reconocido músico y pedagogo, muy vinculado a la actividad musical del ejército. Varias de sus composiciones tuvieron un marcado sentido halagador hacia la monarquía francesa y española, y especialmente el tema de la conquista de Tetuán fue algo recurrente en su catálogo de composiciones ${ }^{55}$.

Aquí la acción se traslada a los momentos previos a la irrupción española en Tetuán, y pone en escena el tema de la muerte en el campo de batalla, siempre a manos del enemigo. En relación a esto último, los historiadores actuales han llegado a la conclusión de que gran parte de la numerosa cantidad de bajas que sufrió España durante esta contienda, se debió tanto a las epidemias de cólera que asediaban al ejército y por la falta de recursos médicos y sanitarios, como por fuego árabe ${ }^{56}$. La epidemia apareció al comienzo de la guerra, dándose los primeros casos el 21 y 22 de noviembre de 1859 entre las tropas acantonadas en el Serrallo ${ }^{57}$. Esto induce a pensar que el libreto peca en una preocupante manipulación del público en lo que al desarrollo de los acontecimientos en África se refiere. Puede que no de una forma consciente, sino por los datos sesgados que la Corona y el gobierno permitían publicar en la prensa a modo de crónica de la guerra ${ }^{58}$.

54 CORTIZO RODRÍGUEZ (1995): op. cit.

55 Además de este episodio cómico-lírico escribió La batalla de Tetuán, una polka para piano en homenaje al general Prim y otra composición con un título análogo para banda, ambas estrenadas el mismo año de 1860. Poner GALBIS LÓPEZ (2002): 6, 964-965.

56 SERRALLONGA URQUIDI, 29: (Madrid,1998): 139-159.

57 MARTÍN SIERRA, 3, 70 (Madrid, 2014): 157-173. https:// dx.doi.org/10.4321/S1887-85712014000300005 [consultado 29-032017].

58 El día 12 de noviembre, una circular de Posada Herrera impone como única fuente de información los partes oficiales que distribuye el Ministerio en las tablillas; al mismo tiempo da instrucciones precisas a los gobernadores para que secuestren toda información que pueda ser considerada como atentatoria. Primero desarma a los escasos medios
El argumento, que en este caso sí dispone grandes masas de intérpretes sobre el escenario para simular los enfrentamientos bélicos, insiste sobre el orgullo que debería suponer para un soldado morir sirviendo a los intereses de España. La reina Isabel II adquiere en esta obra una presencia constante a través de los vítores en su honor que, de una manera muy afectada, llevan a cabo los personajes bien antes de entrar en batalla o al morir peleando. Asimismo, la guerra tiene en este episodio lírico la cualidad de redimir las faltas anteriores cometidas por aquellos que deciden ir a combatir contra el ejército árabe a Marruecos. Es lo que ocurre en el caso del personaje de Jelemeje, un español que por cometer un asesinato de un superior decide huir a África y entrar en las filas de los marroquíes, pero al final accede a colaborar con el ejército español aportando información sobre el enemigo y el terreno, y consigue expiar así su pena. Finalmente, este título recoge también el testimonio de las madres de los militares que, de un modo idealizado, están dispuestas incluso a sacrificar a sus hijos en favor del bien de la nación:

$$
\begin{gathered}
\text { Hijo mío, mi dolor } \\
\text { el corazón me tortura, } \\
\text { más sufriré mi amargura } \\
\text { porque cumplas con honor }{ }^{59} \text {. }
\end{gathered}
$$

Desgraciadamente, una vez más la partitura del compositor valenciano Carlos Llorens se encuentra desaparecida, consecuencia de la limitada circulación y la menor difusión que las partes musicales tenían durante las décadas centrales del siglo XIX.

\subsubsection{La Toma de Tetuán. Un triunfo más para España. La opulencia de la guerra}

Esta zarzuela grande respalda la hipótesis de que las iniciativas locales fueron un elemento muy importante para la exaltación nacional en el teatro lírico durante esta guerra. Su estreno en el Teatro Principal de Córdoba no está claro, aunque se piensa que ocurrió en los días sucesivos a la irrupción española en Tetuán. Los autores literarios de este título fueron Luis María Ramírez de las Casas-Deza, licenciado

refractarios a la intervención, después aumenta la convicción de las hazañas y, finalmente, justificará y creará ilusorios logros en la rendición de los marroquíes y en la firma del tratado de paz. SERRALLONGA URQUIDI, 29: (Madrid,1998): op. cit. 145.

59 La toma de Tetuán. Episodio lírico-dramático en 2 actos. Alba, Juan de, Madrid, Imprenta de José Rodríguez, 1860, BNE, T/27037, p. 23. 
en medicina e historiador por vocación, que ejercía como catedrático de instituto en esta misma ciudad ${ }^{60}$. Junto a él colaboró supuestamente Enrique Márquez -aunque posiblemente pudo haber utilizado un seudónimo-, empleado de Hacienda sobre el que no se han localizado más datos sobre su actividad.

De escribir la partitura se hizo cargo el compositor Manuel Nieto que tenía entonces 15 años. De formación musical castrense, La toma de Tetuán constituyó su primera obra lírica, y comenzó con ella una carrera en el mundo teatral que desarrollaría más extensamente en las décadas finales del siglo XIX, dentro ya del contexto del género chico ${ }^{61}$. En este caso, y a diferencia de los dos libretistas anteriores que sí manifiestan un interés marcado por dar la imagen de una España grandiosa, no debería entenderse en el caso de Nieto como una declaración de sus ideales, sino como su primera oportunidad laboral, ya que nunca se manifestó respecto a la Guerra de África, aunque deja entrever en sus palabras que, visto con retrospectiva en el año 1915, esta victoria no contribuyó ni un ápice a mejorar la vida de la gente corriente ${ }^{62}$.

Nieto en sus memorias ${ }^{63}$ califica este título como una zarzuela de circunstancias que únicamente tardó una semana en escribir. A pesar de que señala también que sólo se representó en dos funciones, el diario La alborada de Córdoba, apunta que se programó nuevamente en el mismo teatro los días $10^{64}$ y $14^{65}$ de junio de 1960 a petición popular, meses después incluso de la conquista de Tetuán en febrero y del fin de la guerra en abril.

El argumento de esta zarzuela, que aparece asiduamente en la bibliografía sobre la música y la literatura en la Guerra de África, transcurre amparándose en el modelo de zarzuela grande dividida en 3 actos, con 13 números musicales que en la actualidad se encuentran perdidos. Sus autores decidieron dedicársela nuevamente al general O’Donnell, algo que no es excepcional en absoluto, ya que el primer Duque de Tetuán, junto a la reina Isabel II, fueron los dos personajes más encumbrados durante el transcurso de toda la guerra y más aún tras la victoria.

Todo el asunto de La toma de Tetuán transcurre durante el tiempo que dura el asedio en tierras árabes, con personajes

60 Aunque La toma de Tetuán no se incluye porque debió firmar con seudónimo ya que su nombre no se corresponde con el manuscrito ni la edición, ya citada, custodiado en la Biblioteca Nacional, pueden consultarse algunas de sus publicaciones en PASAMAR ALZURIA. PEIRÓ MARTÍN (2002): 511-512.

61 Véase GARCÍA TORRES (2012).

62 Véase RAMÍREZ DE ARELLANO (1912).

63 NIETO (1915).

64 ANÓNIMO, 166 (Córdoba, 1860): 3.

65 ANÓNIMO, 169 (Córdoba, 1860): 3. vinculados a la actividad bélica pertenecientes a los dos bandos $^{66}$. El libro describe una vez más a los musulmanes como unos fanáticos, con la particularidad además de que insiste reiteradamente en la conversión al cristianismo de éstos ${ }^{67}$. No hay apenas acción en la trama, sino más bien una exaltación de los beneficios materiales que reporta la guerra a los propios soldados por el hecho de participar en ella.

"Aguardiente, ron, ginebras y panal... roscas mantecados, queso del Prior y algunos pescados [...]. Nada falta, entre cristianos" $"$.

Todo es un alarde constante de opulencias ante la escasez y privación con la que buscaban relacionar la cultura musulmana. Este enaltecimiento de la vida militar llama la atención, más si cabe, debido a la opinión consensuada que existe entre los historiadores hoy en día, quienes afirman que, en la Guerra de África, el cólera y las condiciones insalubres con las que también debían luchar los soldados españoles, ocasionaron más bajas incluso que el fuego enemigo ${ }^{69}$. La propaganda pro-bélica es continua en esta zarzuela, habla incluso de la supuesta suerte que tuvo el ejército español al contar con una equipación armamentística inmejorable, cuando la realidad del campo de batalla, al igual que ocurrió en la Guerra de Cuba, fue muy distinta.

En esta obra no hay acción argumental propiamente dicha, sino más bien una sucesión de consignas e ideales que sustentan la guerra. Recala nuevamente en asuntos utilizados en otros títulos, como el cristiano que por circunstancias ajenas decide irse a Marruecos, aunque detesta todo lo que allí ve y no duda en ayudar al ejército español. También aparece nuevamente el tema de la mujer musulmana, seductora y envuelta en un halo exótico.

66 Un brigadier, un capitán, un teniente, un sargento, un cabo, un soldado, ordenanza, Mohamet, Gevit, Zaida, Isabel. Oficiales, soldados de diferentes armas, moros, moras, cantineras, presidiarios, trabajadores, charangas, cornetas, clarines y tambores. La toma de Tetuán o Un triunfo más para España. Zarzuela en tres actos y en verso, Ramírez Enrique, Córdoba, 1860, [manuscrito] BNE, T/13049.

67 LECOUYER. SERRANO (1979).

68 La toma de Tetuán o Un triunfo más para España, op. cit.

69 Aunque es cierto que cronistas coetáneos a la guerra, como Nuñez de Arce en Recuerdos de la campaña de África. NUÑEZ DE ARCE (1860). Ya dejaron constancia de los incidentes con el cólera, si bien son tratados desde una postura de superación ante la adversidad y da la impresión de que se les resta importancia. No ha sido hasta tiempos recientes cuando han empezado a aparecer las cifras reales de combatientes por culpa del cólera. ROMERO, 49 (Bizkaia, 2014): 619-644. 


\subsection{El ángel de Tetuán ${ }^{70}$. España demanda un lugar en Europa}

Los amores entre miembros pertenecientes a dos bandos enfrentados se suceden a lo largo de la historia del teatro universal, y el Romanticismo fue un periodo especialmente sensible en su difusión. Por ello, no es de extrañar que este tema despertase también la inspiración de los autores precisamente en el contexto de un enfrentamiento como fue el de la Guerra de África.

$\mathrm{El}$ argumento de El ángel de Tetuán, pieza lírico-dramática en 2 actos y un prólogo, estrenada en Zaragoza el 1 de enero de 1860, se inspira precisamente en la historia de amor prohibido entre un español y una marroquí durante los días en los que el ejército se aproxima a la ciudad de Tetuán. Son el brigadier Ricardo y la mora Zulima, quien finalmente termina renegando de la religión islámica en la que ha sido criada por su padre, a quien describe como un fanático que la obliga a adoptar creencias absurdas con las que no se identifica, tal como ella misma añade.

El discurso que proclaman los soldados españoles en este texto pretende alejarse de la imagen de conquista bélica usual, en la que existe un sometimiento por parte de los nativos, y busca concienciar al público del honor y la integridad de las tropas vencedoras. Insta a los españoles a respetar las propiedades de los habitantes de Tetuán, con lo que refleja una imagen de soldado justo, la misma que Alarcón deja intuir al lector cuando describe las quejas que los hebreos residentes en la ciudad elevaban contra los moríos que les habían saqueado ${ }^{71}$.

El posicionamiento de España en Europa y en el panorama internacional fue otra de las estrategias propagandísticas del régimen de Isabel II para convencer a la población de las ventajas que tendría la victoria en África. Esta zarzuela también se hace eco de ello a través de sus versos:

\section{Por Europa tal vez envidiada ya España será respetada ${ }^{72}$}

En lo tocante a este tema, señala posteriormente Galdós en Aita Tettuanen ${ }^{73}$, el grado de astucia política del go-

70 Se sabe que pasó la censura porque aparece publicado en ANÓNIMO, 191 (Barcelona, 1860): 4.

71 ALARCÓN, PALORMO (ed.) (2005): op. cit. Cabe aclarar también que Moríos era el nombre que los hebreos de Tetuán pusieron a los moros.

72 El ángel de Tetuán, pieza lírico dramática en dos actos y un prólogo, Faura y Casanova, música de Narciso Anglada, Zaragoza, 1860, [manuscrito] BNE, MSS/14219/19.

73 PÉREZ GALDÓS (1904). http://www.cervantesvirtual. com/obra-visor/aita-tettauen--0/html/ff415130-82b1-11df-acc7002185ce6064_2.html [Consultado el 25-03-2017]. bierno de O’Donnell para ganar adeptos a la causa bélica con el eslogan de que la guerra sería una oportunidad para España de mejorar su imagen ante el resto del continente europe $^{74}$. Los recientes estudios que, desde el punto de vista político, se han desarrollado en lo tocante a la Primera Guerra de África, hacen alusión al complejo de inferioridad y al sentimiento de exclusión que existían a mediados del XIX, en el que España había perdido su hegemonía como potencia imperial. La prensa era el medio que difundía las preocupaciones de las clases políticas por la pérdida de territorios en el extranjero, que trajo con ello también la pérdida de la hegemonía del continente y el enfrentamiento con Marruecos fue una estrategia para tratar de ponerle freno ${ }^{75}$.

La composición y recepción de El ángel de Tetuán vuelve a circunscribirse a un área local, en este caso Zaragoza. También los autores, Antonio Saura y Casanova del libro y Narciso Anglada de la partitura, son personajes secundarios para la historia del teatro lírico español. Del libretista sólo hay información de la existencia de algunas obras recogidas en el catálogo de la Biblioteca Nacional de España, y del compositor tampoco hay datos, aunque se sabe que ejerció como maestro de Capilla y organista en la Colegiata de Santa María la Mayor de Calatayud (Zaragoza) entre 1870 y $1874^{76}$.

\subsection{Los Voluntarios. Tetuán regresa a la actualidad política y teatral con la Guerra de Margallo (1893-1894)}

Esta zarzuela cómica en un acto de Gerónimo Giménez es la única excepción que realmente tuvo éxito -únicamente de público, no de crítica- de todo el conjunto de títulos escritos sobre la Primera Guerra de Marruecos que se abordan en este trabajo, por lo que ya ha sido objeto de estudio con anterioridad ${ }^{77}$. Su estreno tiene lugar el 28 de julio de 1893 en el Teatro Príncipe Alfonso de Madrid ${ }^{78}$, y constituye un reconocimiento más a los Voluntarios catalanes que a las órdenes del General Prim reforzaron a las tropas enviadas a África, y tomaron el campamento de Muley-Ahmed en 1860. De nuevo la inspiración teatral de esta zarzuela de Fiacro Yrayzoz y Giménez viene dada por uno de los episodios épicos de la guerra de 1859. No obstante, la imagen de los Voluntarios al término del siglo se fue deteriorando

\footnotetext{
74 LÓPEZ BARRANCO (2006).

75 SÁNCHEZ-MEJÍA RODRIGUEZ, 162 (Madrid, 2013): 41.

76 Véase Gran Enciclopedia aragonesa. Calatayud, Archivos musicales. <http://www.enciclopedia-aragonesa.com/voz.asp?voz id $=13335>$ [Consultado 26-03-2017].

77 IBERNI (2006): vol. 2, 939-941.

$78 \mathrm{Ibid}$.
} 
a medida que ascendía el movimiento catalanista, mientras las acciones pasadas llevadas a cabo por estos soldados eran utilizadas como instrumento cohesionador por el ejército ${ }^{79}$. Los autores dedicaron esta vez su obra al Ayuntamiento de Barcelona, y teniendo todo ello en cuenta, no parece un hecho al azar.

La acción de esta zarzuela no se desarrolla en África sino en Aragón, por donde supuestamente pasan los Voluntarios catalanes que viajan a tierras marroquíes. Toda la obra está llena de personajes humildes de origen popular. El enredo amoroso, y en menor medida, la sátira clerical que protagoniza el sacristán Melitón, son los temas que están presentes en ella, a lo que hay que añadir la apología bélica de la última escena en la que se recrea a los voluntarios en la batalla contra Muley-Ahmed. En Los Voluntarios sí tuvo importancia el componente espectacular, y gran parte del éxito de este título fue gracias a él ${ }^{80}$.

A pesar de la buena recepción de público, el episodio del 59 demostró ser un tema agotado y de poco interés social en la década de 1890. Cuando en este momento la prensa de Barcelona intentó rememorarlo en sus publicaciones para caldear los ánimos ante un nuevo enfrentamiento apenas tuvo éxito ${ }^{81}$ y es realmente limitado el número de obras líricas que con esta temática aparecen entonces. En el año 1893, en que se estrena este título, se dio la circunstancia de que también se llevaron a cabo homenajes similares en honor de los casi quinientos militares que estuvieron a las órdenes de Prim. Un ejemplo de ello fue que la función del día 4 de febrero, en el teatro Tívoli de Barcelona, se dedicase a los Voluntarios Catalanes de África ${ }^{82}$. Este clima de ensalzamiento vino condicionado por las tensiones que desataron una nueva intervención en Marruecos, la conocida como Guerra de Margallo.

Así que en esta obra confluyen por una parte los intereses propagandísticos del gobierno central y los intereses económicos del entonces empresario del Príncipe Alfonso, Guillermo Cereceda. Junto a ello hay que añadir la crispación general debido a las agresiones que sufría Melilla por los rifeños ${ }^{83}$ y los homenajes en honor de los soldados catalanes a quienes se consideraba héroes nacionales. Los Voluntarios, al inscribirse formalmente dentro del fenómeno del género chico, llegaba a un teatro más democrático y con un público más heterogéneo que los títulos estrenados a mediados de siglo.

La partitura ${ }^{84}$ de Giménez destaca por su carácter marcial, recurre reiteradamente al uso del pasodoble en aquellos números que hacen alusión al ejército. No sólo el $\mathrm{n}^{\mathrm{o}} 3$, el más famoso de la obra, que anuncia con júbilo la llegada de los Voluntarios al pueblo, sino también en la última sección del dúo cómico entre el sacristán Melitón y Rosita, y ella le rechaza porque prefiere un militar.

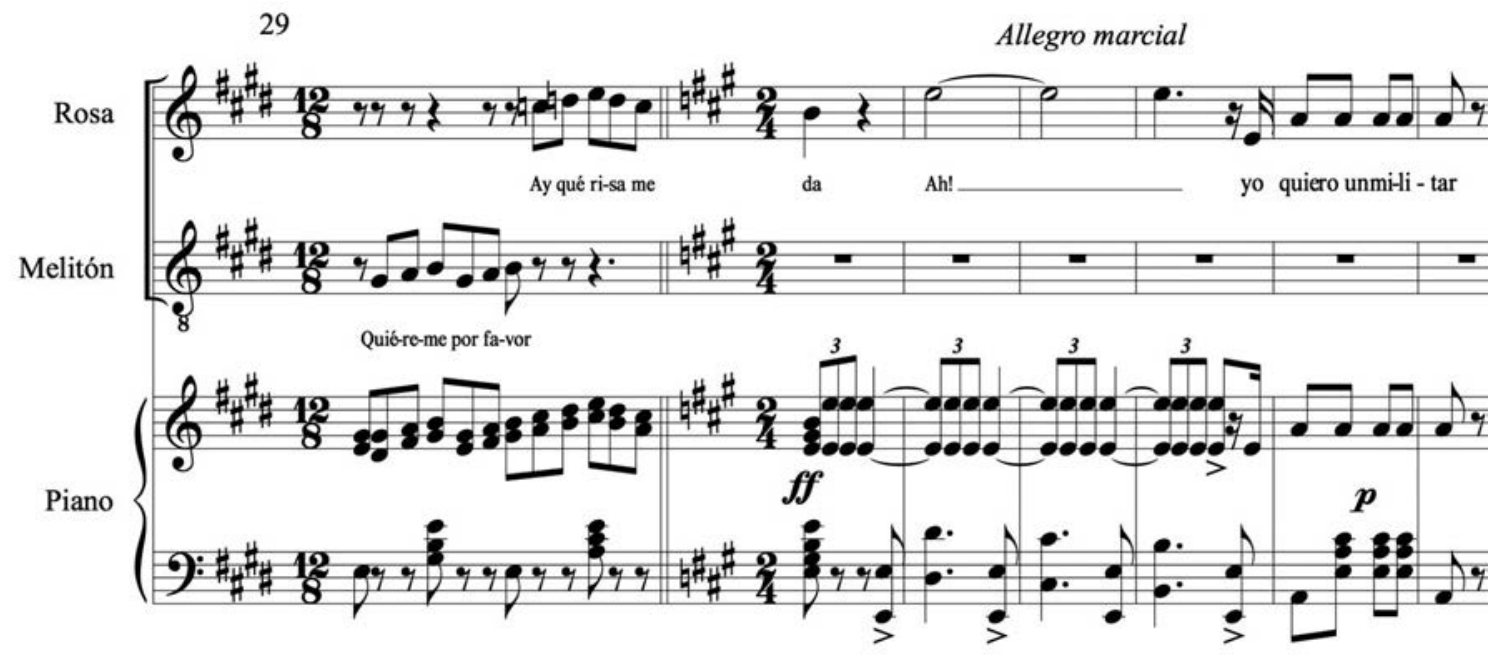

Ejemplo 2. N 4. Dúo de Rosa y Melitón. “Aquí estoy Rosita...” (cc. 29-35).

79 GONZÁLEZ CALLEJA, 14 (Madrid, 2005): 119-164. 80 Véase IBERNI (2006): vol. 2, 939-941.

81 GARCÍA-BALAÑ̂̀, vol. 2, 12 (Bologna, 2016): 1-24.

$<$ DOI: http://storicamente.org/garcia balana migracion imperio espanol $>$ [Consultado 04-04-2017].
82 ANÓNIMO, 4.634 (Barcelona, 1893): 4. 83 NÚÑEZ FLORENCIO. ESPADAS BURGOS (1990).

84 Puede consultarse con mayor detalle cada uno de los números que constituyen esta obra en Véase IBERNI (2006): vol. 2, 939941. 
Asimismo, el $\mathrm{n}^{\mathrm{o}} 6$ es otro pasodoble instrumental que sirve para acompañar en escena la batalla dramatizada de la última escena. La orquestación, en la que sobresale la intervención de la caja y la sección de metales, está orientada a aportar mayor dramatismo y espectacularidad en la apología bélica que pone fin a la obra.

\subsection{La batalla de Tetuán. Recuerdos de un pasado glorioso}

En 1898, cuando el Desastre era ya inminente, la Guerra de África volvió a la mente de los españoles. Un examen poco exhaustivo de la prensa del momento, en la que abundan testimonios, relatos y homenajes de numerosos implicados en el enfrentamiento, deja entrever aún la contemporaneidad del asunto. En el teatro lírico español va a ser algo habitual el rememorar durante los conflictos sucesivos el triunfo de 1860 , en cierta medida por el clima social favorable que afloró. Durante el transcurso de la guerra con Marruecos se pusieron en escena obras que recordaban la disputa de la Independencia con los franceses. Sobre esto se centra El capitán español ${ }^{85}$, una zarzuela grande estrenada en el Teatro de la Zarzuela en 1859 que, con una temática amorosa, lleva a cabo una exaltación del ejército y de la supremacía española contra los franceses tanto en la batalla como moralmente, cuando se les perdona la vida a pesar de su traición durante la reyerta.

Algo similar ocurrió en 1898 con La batalla de Tetuán ${ }^{86}$, zarzuela cómica en 1 acto. Su acción se desarrolla en un pueblo localizado en las inmediaciones de Madrid llamado Tetuán ${ }^{87}$. África aún seguía presente en la sociedad española de 1898 , en cierta medida gracias a la prensa, que publicaba memorias y conmemoraciones de estos sucesos, pero ya de un modo más distendido y anecdótico que en décadas anteriores. El libreto de Perrín y Palacios sustituye la temática bélica presente en los títulos de mediados de siglo y la demonización enemiga por una historia de enredo amoroso. Este título, inmerso en el ya plenamente desarrollado sistema del teatro por horas, rehuye el patriotismo exacerbado de

85 El capitán español. Zarzuela en 3 actos con música de Luis Cepeda. Ramos, Pedro Enrique, Madrid, Imprenta de J. M. Ducazcal, $1859, \mathrm{BNE}, \mathrm{T} / 8953$.

86 Estrenada en el Teatro El Dorado de Madrid el 21 de julio de 1898. Véase La batalla de Tetuán. Zarzuela cómica en 1 acto y 3 cuadros, Perrín, Guillermo, Palacios, Miguel de, Madrid, R. Velasco, $1898, \mathrm{BNE}, \mathrm{T} / 15362$.

87 La localización de la obra es real, Tetuán a comienzos del siglo XX era un poblado de mayoría obrera localizado en el extrarradio de Madrid, que aún estaba en plena expansión. Véase CARDONA HERRERO. GÓMEZ CEBALLOS (1982). las obras anteriores, y lo remplaza por escenas costumbristas y cómicas, en la línea del sainete finisecular. El pueblo de Tetuán, los bailes nocturnos y lugares emblemáticos de Madrid contextualizan toda la acción de la obra. A pesar de que el texto descalifica puntualmente a los moros, el enfrentamiento que comenzó en 1859 se banaliza aquí, y sirve como un simple juego de palabras que pone en relación los sucesos de la Guerra de África con la disputa que se forma entre los dos pretendientes de Rita.

$$
\begin{array}{ll}
\text { Rita. } & -i \text { Qué es esto? } \\
\text { Lucas. } & -i \text { Qué ocurre? } \\
\text { Cachorra. } & -i \text { En mi casa? (Gran confusión. Todos } \\
& \text { se pegan. Sotero quiere pegar a Antonio } \\
& \text { y pega al señor Lucas, y éste lo coge y lo } \\
& \text { mete dentro del caldero de los charros. } \\
& \text { Felipa contiene a Gumersindo y a Pepe. } \\
& \text { Los músicos con los instrumentos bajan } \\
& \text { del tablao.) } \\
\text { Sotero. } & - \text { ¿Ay, lo mío! ¡todo en el mismo sitio! } \\
\text { Cachorra. } & - \text { Pero, a ver, ¿es esto la batalla de Te- } \\
& \text { tuán, ú qué? }
\end{array}
$$

\begin{tabular}{|c|c|}
\hline $\begin{array}{l}\mathrm{N}^{\circ} 1 \text {. Mazurca y coro. "Por ser la fiesta de las } \\
\text { victorias" }\end{array}$ & \multirow{7}{*}{1 acto } \\
\hline $\begin{array}{l}\mathrm{N}^{\circ} 1 \mathrm{~B} \text {. Pasacalle. "La banda militar ya viene por } \\
\text { ahî" }\end{array}$ & \\
\hline $\mathrm{N}^{\circ}$ 2. Duo. “¿Por qué llevas ese paso tan ligero?" & \\
\hline No 3. Polka. "Que viva la alegría" & \\
\hline $\begin{array}{l}\text { No 3B. Danza americana. "Que nos cante la } \\
\text { Felipa ahora mismo una canción". }\end{array}$ & \\
\hline $\mathrm{N}^{\circ}$ 4. Mazurca. "En la bolera hay que buscarle" & \\
\hline $\begin{array}{l}N^{\circ} 5 \text {. Schotis. “¿Con que no ha tenido a bien } \\
\text { concederme a mí el chotis?" }\end{array}$ & \\
\hline
\end{tabular}

La partitura de La batalla de Tetuán apenas presenta novedad en comparación con otras obras similares pertenecientes al género chico, que presentan asimismo una yuxtaposición de números musicales contextualizados en lo que Ramón Barce denominó folclore urbano de moda ${ }^{88}$.

Tabla 3. Danzas urbanas que incluyen La batalla de Tetuán y organización formal. 
Esta zarzuela incluye una banda militar, soldados en escena y varios números de carácter marcial, con la particularidad de que aquí es el coro femenino quien los interpreta, a diferencia de los títulos anteriores. A pesar de ello, no hay una inclinación sicalíptica explícita en las escenas. El pa- sodoble de carácter militar $\left(\mathrm{N}^{\circ} 1 \mathrm{~B}\right)$, en el que se menciona a la fiereza árabe y se exalta el pueblo de Tetuán, es el número que centró la atención de la prensa por su espectacularidad escénica.

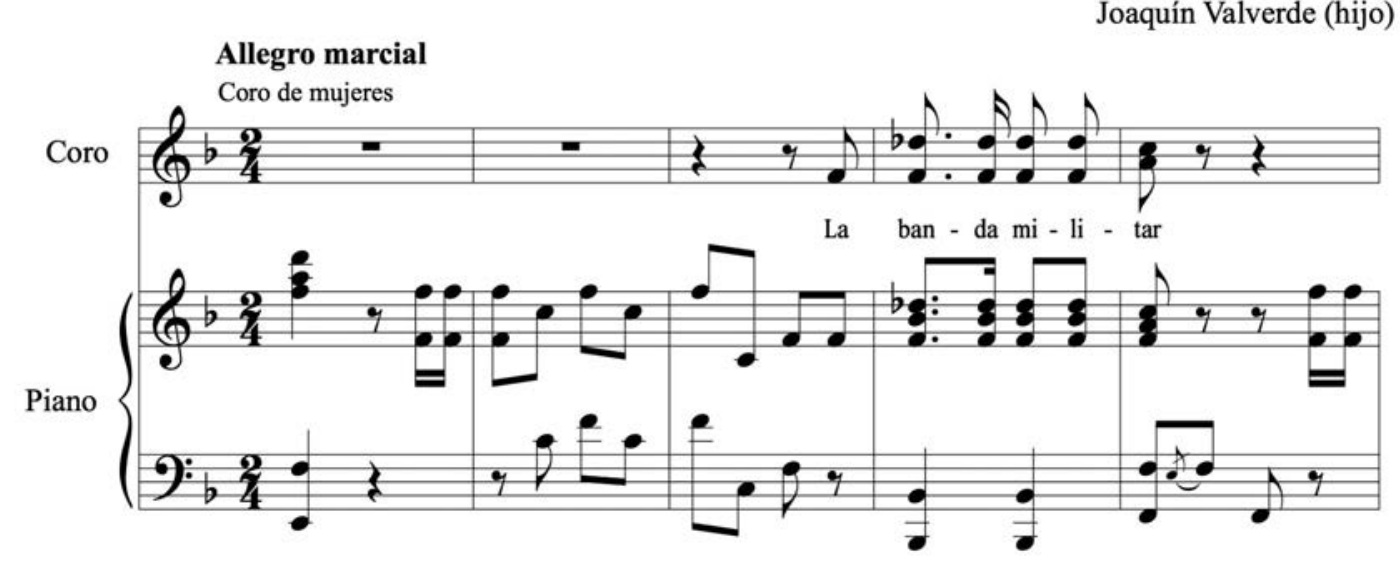

Ejemplo 3. La Batalla de Tetuán, comienzo no $1 \mathrm{~B}$ (cc.1-5).

La recepción de este título no fue unánime, los comentarios en los diarios fueron muy distintos. Por un lado, está la crítica por la falta de originalidad de este sainete, algo muy común en las crónicas del género chico, aparecida en el diario El Globo. En el otro extremo, La Correspondencia de España, en su línea benevolente, la cataloga como "una de las mejores obras del género chico venidas a la escena en los últimos años" $"$. Ninguno de los artículos consultados hace alusión alguna al acontecimiento de África en 1860, por lo que no se estableció un proceso de interpelación con el público contemporáneo como cabría esperar, para que éste recuperara el fervor social en pro de la guerra de mediados de siglo y consiguiese perpetuar el patriotismo implícito de las obras anteriores.

\subsection{La Misa de Gallo. El conflicto bélico en la distancia}

Más alejada en el tiempo se sitúa este melodrama en 2 actos con letra de Luis de Larra y Ramón Asensio Más, con música de Tomás López Torregrosa ${ }^{90}$. El estreno de esta

89 ANÓNIMO, 14.780 (Madrid, 1898): 2.

90 La Misa del Gallo. Melodrama en 2 actos, Larra, Luis de, Asensio, Ramón, Madrid, Sociedad de Autores Españoles, 1913, Archivo SGAE. última obra tiene lugar en el Teatro Cómico de Madrid, el 15 de febrero de 1913 por la compañía de Enrique Chicote y Loreto Prado ${ }^{91}$. Vuelve a coincidir con las novedades que llegan desde África, ya que el 30 de marzo de 1912 se firma el Tratado de Fez, por el que se reconoce a España el dominio sobre el territorio del norte de Marruecos, estableciéndose la capital en Tetuán. Fue precisamente en febrero de 1913 cuando las tropas españolas comenzaron a invadir esta ciudad de forma pacífica ${ }^{92}$; el paralelismo entre los años de 1860 y 1913 es evidente, y esta zarzuela lo manifiesta.

La función de esta obra tiene un sentido más recordatorio y menos patriótico que las escritas en torno a la Primera Guerra de Marruecos. Los moros, a pesar de seguir siendo el enemigo a abatir, no tienen en el texto descalificación alguna, lo que deja en evidencia que los ánimos ya no estaban tan encendidos. La trama argumental, localizada en un campamento militar español en Marruecos en el año 1859, habla sobre la traición entre militares al ofrecer armas al enemigo, pero todo ello viene propiciado por el odio entre dos rivales para conquistar a Amparo. Nuevamente se trata de una temática sainetesca en la que los sentimientos derivados por el amor y el desamor son los que condicionan los comportamientos de

91 ANÓNIMO, 6.169 (Madrid, 1913): 3.

92 TUSSEL, et al (eds.) (2000). 
los personajes principales, y rigen en última instancia toda la obra. Más que de teatro patriótico, en el sentido beligerante de algunos de los primeros ejemplos, se busca construir un episodio nacional amable, lleno de comicidad y con un enredo amoroso, desarrollado en una localización exótica que atrajese la atención del público.

La partitura de La misa de Gallo también es sintomática del distanciamiento temporal que existía con la Guerra de África del 59 aunque el tema volviese a estar de actualidad. Se reduce el carácter hímnico y militar de su música para adherirse a lo esperado en una obra deudora del género chico, en el sentido de que se hace acopio de una sucesión de danzas populares y ritmos que estaban de moda al término del XIX, y abundan los números musicales que remiten a la estructura formal del cuplé.

$$
* * * * * * *
$$

A lo largo de este trabajo se ha podido ver el grado de transcendencia política que tiene la zarzuela en sus diferentes tipos. En relación a la Primera Guerra de África, el teatro lírico ha sido una herramienta muy útil para crear la predisposición social favorable al conflicto que marcó los años de 1859-60. El hecho de que la mayoría de títulos que se han estudiado sean iniciativas locales, deja en evidencia la falta de estrategias del gobierno de O’Donnell en materia teatral, y también a la hora de desarrollar un plan propagandístico a nivel nacional con el que beneficiarse en su postura pro-belicista. No obstante, esto se suplió mediante el control ejercido sobre la prensa, que sí condicionó enormemente la temática e ideología presentes en estas obras líricas, en las que todos los argumentos que la élite dominante del gobierno enarboló como justificante para iniciar la guerra contra Marruecos son tratados del mismo modo en la escena lírica.

\section{BIBLIOGRAFÍA}

Anónimo, "Diversiones públicas", Diario Oficial de Avisos de Madrid, 80 (Madrid, 1859): 4.

- "Espectáculos teatrales", La Iberia, 1.708 (Madrid, 1860): 4.

- "Guerra de África", El Correo de Ultramar, 376 (París, 1860): 181

_ "Tamborilazos", El Nene, 11 (Madrid, 1860): 84.

- "Gacetilla de Madrid", La España. Madrid, 4.143 (Madrid, 1860): 4

- "Sección de anuncios", El Isleño, 913 (Mallorca, 1860): 4.

— "Teatro", La Alborada, 166 (Córdoba, 1860): 3.

_- "Teatro", La Alborada, 169 (Córdoba, 1860): 3.
- "Gacetilla", La Corona, 191 (Barcelona, 1860): 8.

- "Espectáculos", La Dinastía, Barcelona, no 4.634 (Barcelona, 1893): 3-4.

_ "En El Dorado", La Correspondencia de España, 14.780 (Madrid, 1898): 2.

— "Los teatros", Heraldo militar, 6.169 (Madrid, 1913): 2.

Alarcón, Pedro Antonio de, María del Pilar Palomo (ed.), Diario de un testigo de la Guerra de África, Sevilla, Fundación José Manuel Lara, 2005.

Albert Garcia-Balañà, Migración y Milicia en la España trasatlántica del siglo XIX: auge y caída del imperialismo popular, "Storicamente", 12 (Bologna, 2016): $1-24$.

Althusser, Louis, Ideología y aparatos ideológicos del estado, Buenos Aires, Nueva visión, 1988.

Álvarez Junco, José, Mater Dolorosa, Madrid, Taurus, 2001a.

Álvarez Junco, José, "El nacionalismo español: las influencias en la acción estatal", Historia social. La construcción imaginaria de las Comunidades Nacionales, 40 (Valencia, 2001b): 29-51.

Cárdenas Isasi, Jaime, “ «iOh qué hermoso es el país de África!». El colonialismo español en Marruecos en la zarzuela del primer tercio del siglo XX", Tobias Brandenberg, Antje Dreyer (eds.), La zarzuela y sus caminos. Del siglo XVII a la actualidad, Berlín, LIT Ibéricas, 2016, vol. 8: 217-235.

Cardona Herrero, Sergio, Gómez Ceballos, Buenaventura, Apuntes para una historia de Tetuán, Madrid, Ayuntamiento de Madrid, Junta Municipal del Distrito de Tetuán, 1982.

Carpentier, Alejo, Ese músico que llevo dentro, Madrid, Alianza, 1987.

Carrasco González, Antonio M., El reino olvidado: Cinco siglos de historia de España en África, Madrid, La esfera de los libros, 2012.

Casares, Emilio, Francisco Asenjo Barbieri, vol. 2. Escritos, Madrid, ICCMU, 1994.

Clausewitz, Karl von, De la guerra, Madrid, La Esfera de los libros, 2005

Cortizo Rodríguez, $\mathrm{M}^{\mathrm{a}}$ Encina, "La zarzuela del siglo XIX: estado de la cuestión", Emilio Casares y Celsa Alonso (eds.), La música española en el siglo XIX, Oviedo, Universidad de Oviedo, 1995: 161-193.

Domingo Acebrón, $\mathrm{M}^{\mathrm{a}}$ Dolores: "Los reformistas cubanos en París 1838-1878”, Caravelle, 74 (Toulouse, 2000): 105-117.

Galbis López, Vicente, "Llorens Robles, Carlos", Emilio Casares (ed.), Diccionario de la Música Española e Hispanoamericana, Madrid, SGAE-ICCMU, 2002, vol. 6: 964-965. 
Gamayo, F., "Espectáculos”, La regeneración, 1.467 (Madrid: 1860$): 4$.

García Torres, Andrea, El género chico a través de la figura de Manuel Nieto (1844-1915): estudio de sus dos obras más representativas "Certamen nacional" y "Cuadros disolventes", Oviedo, Universidad de Oviedo, 2012.

González Calleja, Eduardo, "Bon cop de falç!. Mitos e imaginarios bélicos en la cultura del catalanismo", Historia y política, 14 (Madrid, 2005): 119-164.

Guereña, Jean-Louis, "Analfabetismo y alfabetización en España (1835-1860)", Revista de educación, 288 (Madrid, 1989): 185-236.

Guillamet i Lloveras, Història del periodisme: Notícies, periodistes i mitjans de comunicación, Bellaterra, Universidad Autónoma de Barcelona, 2003.

Iberni, Luis G., "Voluntarios, Los", Emilio Casares (ed.), Diccionario de la Zarzuela. España e Hispanoamérica, $2^{\mathrm{a}}$ ed., Madrid, ICCMU, 2006, vol. 2: 939-941.

Lecouyer, M. C., Serrano, C., La Guerre d'Afrique et ses répercussions en Espagne: ideologies et colonialisme en Espagne 1859-1904, París, Presses Universitaires de France, 1976.

López Barranco, Juan José, El Rif en armas: la narrativa española sobre la guerra de Marruecos, (1859-2005), Madrid, Mare Nostrum, 2006.

Martín Sierra, F., "El papel de la sanidad militar en la campaña de Marruecos (1859-1860)", Sanidad militar, 70, 3 (Madrid, 2014): 157-173.

Moisand, Jeanne, Scènes capitales. Madrid, Barcelone et le monde théâtral fin de siècle, Madrid, Casa Velázquez, 2013.

Nash, Mary, Mujer, familia y trabajo en España, Barcelona, Anthropos, 1983.

Nieto Manuel, Memorias añejas, R. Velasco, 1915.

Núñez Florencio, Rafael, Espadas Burgos, Manuel, Militarismo y antimilitarismo en España (1888-1909), Madrid, CSIC, 1990.

Pasamar Alzuria, Gonzalo, Peiró Martín, Ignacio, Diccionario Akal de historiadores españoles contemporáneos (1840-1980), Madrid, Akal, 2002: 511-512.

Pastor Comín, Juan José, "El conflicto con Marruecos en la música española", Alía Miranda, Francisco (ed.), La Guerra de Marruecos y la España de su tiempo (1909-1927). Ciudad Real, Sociedad Don Quijote de Conmemoraciones Culturales de Castilla-La Mancha, 2009: 197-222.

Pérez Galdós, Benito, Aita Tettuanen, Madrid, Biblioteca Virtual Miguel de Cervantes, 1904.
Pérez Rioja, Bonifacio, Obras escénicas y memorias teatrales, Valladolid, Imprenta castellana, 1906.

Quintero Calvache, Juan Carlos, "El orientalismo y la mirada del Otro. La otredad en el discurso para nuevas formas de penetración colonial", Revista Educación y pensamiento, 22 (Santiago de Cali, 2015): 119-137.

Ramírez de Arellano, Rafael, El teatro en Córdoba, Ciudad Real, Tipografía del Hospicio Provincial, 1912.

Ramón Barce, "El folklore urbano y la música de los sainetes líricos del último cuarto del siglo XIX: la explicitación escénica de los bailes", Revista de Musicología, 16, 6, XV Congreso de la Sociedad Internacional de Musicología: Culturas musicales del Mediterráneo y sus ramificaciones (Madrid, 1993): 3217-3225.

Riquier, Borja, "La débil nacionalización del siglo XIX", Historia Social, 20 (Valencia, 1994): 97-114.

Romero Peña, $\mathrm{M}^{\mathrm{a}}$ Mercedes, El teatro en Madrid a principios del siglo XIX, en especial el de la Guerra de la Independencia, Madrid, Universidad Complutense, 2006.

Romero, Yasmina, "Prensa y literatura en la Guerra de África (1859-1860). Opinión publicada, patriotismo y xenofobia", Historia contemporánea, 49 (Bizkaia, 2014): 619-644.

Salgues, Marie, Teatro patriótico y nacionalismo en España 1859-1900, Zaragoza, Prensas Universitarias de Zaragoza, 2010.

Sánchez-Mejía Rodríguez, Mª Luisa, "Barbarie y civilización en el discurso nacionalista de la Guerra de África (1859-1860)", Revista de estudios políticos, 162 (Madrid, 2013): 39-67.

Sánchez, Víctor, "La habanera en la zarzuela española en el siglo XIX: idealización marinera de un mundo tropical”, Cuadernos de música y artes escénicas, 3,1 (Bogotá, 2007): 4-26.

Serrallonga Urquidi, Ioan, "La guerra de África. Una revisión", Revista Ayer, 29, (Madrid, 1998): 139-159.

Somé Laserna, Caín, "La Guerra de África en Sevilla: fervor patrio y opinión pública", Comunicación en el XI Congreso de la Asociación de Historia Contemporánea. Claves del mundo contemporáneo, Granada, Comares, 2012.

Stucki, Andreas, Las guerras de Cuba. Violencia y campos de concentración (1868-1898). Traducción de Laureano Joaquín Araujo, Madrid, La Esfera de los libros, 2017.

Tussel, Javier (et al.) (eds.), La política exterior de España en el siglo XX, Madrid, Biblioteca Nueva, 2000.

Recibido: 21.04 .2017

Aceptado: 08.08.2017 